\title{
Porosity and Mechanical Strength of an Autoclaved Clayey Cellular Concrete
}

\author{
P. O. Guglielmi, ${ }^{1}$ W. R. L. Silva, ${ }^{2}$ W. L. Repette, ${ }^{2}$ and D. Hotza ${ }^{3}$ \\ ${ }^{1}$ Department of Mechanical Engineering (EMC), Federal University of Santa Catarina (UFSC), 88040-900 Florianópolis, SC, Brazil \\ ${ }^{2}$ Department of Civil Engineering (ECV), Federal University of Santa Catarina (UFSC), 88040-900 Florianópolis, SC, Brazil \\ ${ }^{3}$ Department of Chemical Engineering (EQA), Federal University of Santa Catarina (UFSC), 88040-900 Florianópolis, SC, Brazil
}

Correspondence should be addressed to D. Hotza, dhotza@gmail.com

Received 7 February 2010; Accepted 11 May 2010

Academic Editor: Abir Al-Tabbaa

Copyright () 2010 P. O. Guglielmi et al. This is an open access article distributed under the Creative Commons Attribution License, which permits unrestricted use, distribution, and reproduction in any medium, provided the original work is properly cited.

This paper investigates the porosity and the mechanical strength of an Autoclaved Clayey Cellular Concrete (ACCC) with the binder produced with $75 \mathrm{wt} \%$ kaolinite clay and $25 \mathrm{wt} \%$ Portland cement. Aluminum powder was used as foaming agent, from $0.2 \mathrm{wt} \%$ to $0.8 \mathrm{wt} \%$, producing specimens with different porosities. The results show that the specimens with higher content of aluminum presented pore coalescence, which can explain the lower porosity of these samples. The porosities obtained with the aluminum contents used in the study were high (approximately 80\%), what accounts for the low mechanical strength of the investigated cellular concretes (maximum of $0.62 \mathrm{MPa}$ ). Nevertheless, comparing the results obtained in this study to the ones for low temperature clayey aerated concrete with similar compositions, it can be observed that autoclaving is effective for increasing the material mechanical strength.

\section{Introduction}

Cellular concrete is a hardened Portland cement slurry that has been aerated prior to setting to give a homogeneous void or cell structure containing $50-80$ vol\% or more of air bubbles, void spaces, and capillary porosity [1]. Thermal and acoustic insulation and fire resistance are some of the properties that make cellular concrete a very interesting material for building construction applications [2-4].

There are many possible ways to produce cellular concrete. Different compositions together with different curing methods can be used in order to obtain variable final properties, such as density, mechanical strength and thermal and acoustic conductivity [1].

Final properties of a cellular concrete largely depend on its porosity, which can be modified by changing the foaming agent type and content. A very porous material will present excellent thermal and acoustic insulation properties, due to its high amount of entrained air. However, these properties are achieved to the detriment of mechanical strength, which decreases as the pore volume increases. Therefore, characterization of porosity and its influence on the mechanical strength of cellular concrete is a very important factor to be analyzed in the production of this kind of material.

Some investigations [5] show that, for the same porosity and composition, cellular concrete mechanical strength can be increased by altering the curing method. Autoclaved Aerated Concrete (AAC), that is, cured under steam pressure at temperatures between $180^{\circ} \mathrm{C}$ and $190^{\circ} \mathrm{C}$, normally presents higher compression strength than room temperature moistcured Nonautoclaved Aerated Concrete (NAAC) concretes. In addition, during autoclaving the material achieves its final microstructure, while NAAC undergoes microstructural changes with time and, consequently, slow and gradual changes on its mechanical strength [5].

A kaolinitic clayey-based cellular concrete composition was investigated by Goual et al. [6-8]. In their studies, Clayey Cellular Concrete (CCC), as it was designated, was moist-cured at $20^{\circ} \mathrm{C}$, under relative humidity of $90 \%$. As the reactions between kaolinite and Portland cement are very slow at room temperature, this material can take months until its final mechanical strength is achieved. The innovation proposed in this paper relates with using 
autoclave to enhance the material properties of this kind of cellular concrete.

This study aims particularly at investigating the porosity and mechanical strength of an Autoclaved Clayey Cellular Concrete (ACCC) and compares the results with those presented by CCC with similar compositions, reported in the literature.

\section{Experimental}

2.1. Materials. The clay used was composed of $98.3 \%$ kaolinite (Caulina Minérios, Brazil) and the cement was a standard high initial strength Portland cement (CP V-ARIRS, Votorantim, Brazil). The aluminum powder was Stanlux Flake CL 4010 (Aldoro, Brazil) with an average particle size of $16 \mu \mathrm{m}$. In order to increase the workability of the clay-cement paste, a polycarboxylate-based superplasticizer (Glenium 51, BASF, Germany) was used ( $32 \mathrm{wt} \%$ of solids).

2.2. Compositions. The Autoclaved Clayey Cellular Concrete (ACCC) was obtained through the aeration of an aqueous paste of a kaolinitic clay and Portland cement using aluminum powder as the foaming agent. Aluminum powder reacts with the caustic solution that evolves during the hydration reaction to form hydrogen gas bubbles [7]. At the end of the foaming process, the hydrogen escapes to the atmosphere and is replaced by air, which is kept entrained as bubbles into the paste, becoming spherical pores after the total setting of the cement, originating a cellular structure [6].

Four compositions were analyzed, differing in the amount of aluminum powder used. The amounts, calculated in terms of weight percentage of dry clay-cement materials, were the following: $75 \mathrm{wt} \%$ clay, $25 \mathrm{wt} \%$ cement, $65 \mathrm{wt} \%$ water, and polycarboxylate-based superplasticizer $(0.8 \mathrm{wt} \%$, weight percentage of solids in relation to dry materials), to which amounts of $0.2 \mathrm{wt} \%$ to $0.8 \mathrm{wt} \%$ of aluminum powder were added in increments of $0.2 \%$. The samples in this study were denoted by A2 for 0.2 , A4 for 0.4, A6 for 0.6 and A8 for $0.8 \mathrm{wt} \%$ of aluminum.

2.3. Samples Preparation. In this experiment, clay and cement were dry-mixed in a planetary axis mixer at low speed for 2 minutes. Water was then gradually added while mixing continued at low speed for another 2 minutes. A short stop of 1.5 minutes on mixing was done in order to scrape the material sticked on the walls of the mixing container. The mixture was then homogenized at low speed for 1 minute, followed by a 2 minutes period at high speed. The superplasticizer was added while the mixer was maintained stopped for 30 seconds. After the addition of this additive the paste was mixed at low speed for 1 minute and subsequently stopped for another 30 seconds for the addition of the aluminum powder, which was mixed and homogenized into the paste for 1 minute at low speed.

Eight specimens of each mix were cast into cylindrical $\left(50 \times 100 \mathrm{~mm}^{3}\right)$ metallic moulds, previously oil-lubricated in order to facilitate the demolding. Sixteen hours after molding, the excess expanded portions were cut off. After 48 hours the specimens were removed from the moulds and maintained in a humid room at $25 \pm 2{ }^{\circ} \mathrm{C}$ and $90 \%$ relative humidity for 2 days, being subsequently autoclaved at $180^{\circ} \mathrm{C}$ and 12 atm for 10 hours. The samples were dried in a drying oven at $70 \pm 2^{\circ} \mathrm{C}$, until constant weight was achieved before beginning the experiments.

The microstructures and phases of ACCC were compared to those of a low-temperature clayey cellular concrete, cured at ambient temperature in a humid room at $25 \pm 2{ }^{\circ} \mathrm{C}$ and $90 \%$ relative humidity for 21 days.

2.4. Density, Porosity, and Mechanical Strength. The relative density $\left(\rho_{\text {rel }}\right)$ of the cellular concrete corresponds to the ratio between the apparent density (geometrically measured) of the cellular material $\left(\rho_{\text {ap }}\right)$ and the density of the solid that composes the matrix of this cellular material $\left(\rho_{\text {sol }}\right)$ [9]:

$$
\rho_{\text {rel }}=\frac{\rho_{\text {ap }}}{\rho_{\text {sol }}}
$$

The porosity is given by [9]

$$
P=\left(1-\rho_{\text {rel }}\right) \text {. }
$$

In order to measure the $\rho_{\text {ap }}$ of the ACCC samples, discs of approximately $50 \times 15 \mathrm{~mm}^{3}$ were cut from the center of 2 samples of each composition. Their mass $\left(m_{\text {cel }}\right)$ and the relative dimensions for the volume $\left(V_{\text {cel }}\right)$ calculation were then measured, being the apparent density determined by (3)

$$
\rho_{\text {ap }}=\frac{m_{\text {cel }}}{V_{\text {cel }}},
$$

where $V_{\text {cel }}$ is determined by the geometrical formula for calculating a cylindrical volume.

For measuring $\rho_{\text {sol }}$ a helium pycnometer (Multipycnometer, QuantaChrome, USA) was used. For this analysis, representative samples of each composition were ground. Approximately $4 \mathrm{~g}$ of powder of each composition were used for the measurement. A total of 10 measurements were done for each powder sample, being the final value given by the arithmetical average.

In order to determine the mechanical strength of the specimens, five cylindrical samples $\left(50 \times 100 \mathrm{~mm}^{3}\right)$ of each composition were tested in a universal machine for mechanical tests (DL 20000, Emic, Brazil), according to a Brazilian standard [10]. The base-surfaces of the specimens were covered with plaster of Paris in order to obtain flat and parallel surfaces. The load speed used was $1 \mathrm{~mm} / \mathrm{min}$.

2.5. Microstructure and Phase Analysis. The products in this work were characterized by X-ray diffractometry (XRD, Phillips, model Xpert, The Netherlands), and scanning electron microscopy (SEM, Phillips, The Netherlands).

\section{Results and Discussions}

3.1. Density and Porosity. Figure 1 shows the apparent density and the porosity of the analyzed ACCC samples, 


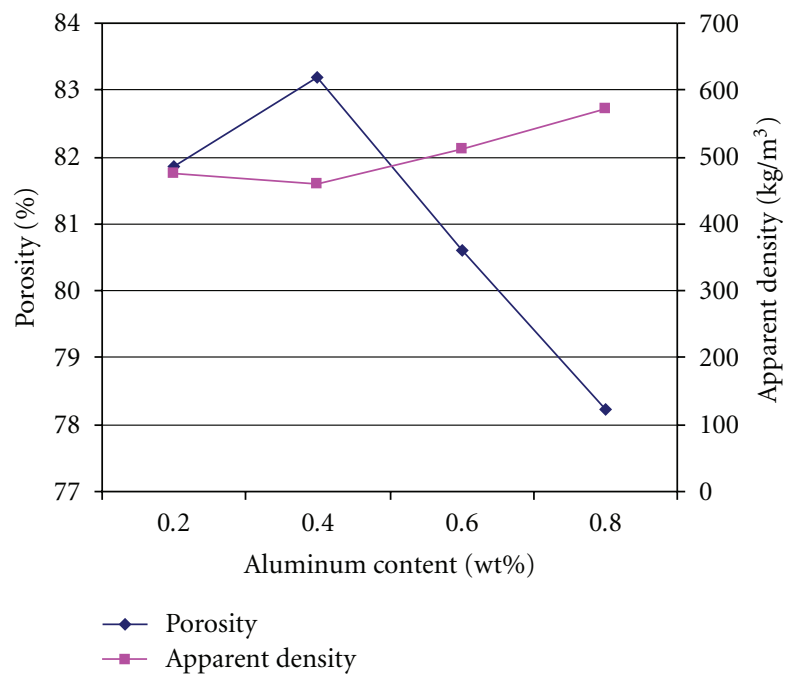

FIGURE 1: Apparent density and porosity of ACCC as a function of aluminum powder content.

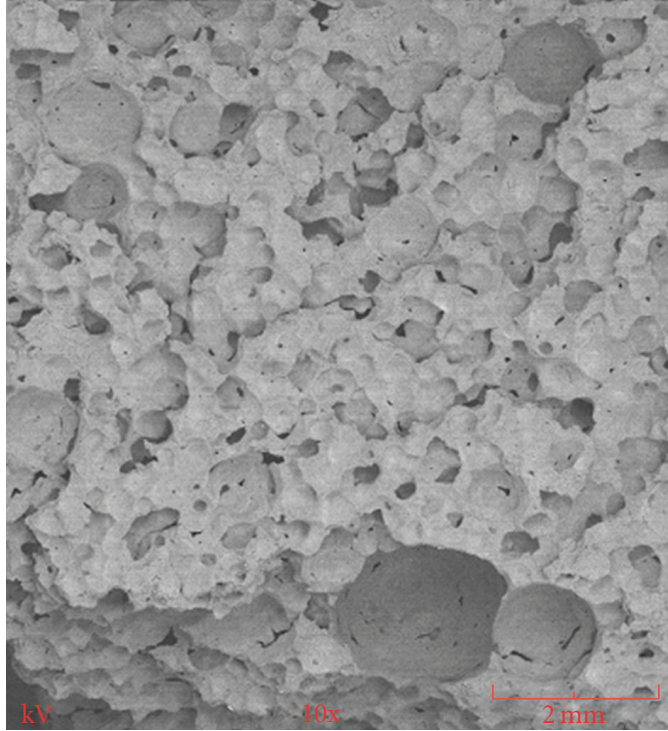

(a)

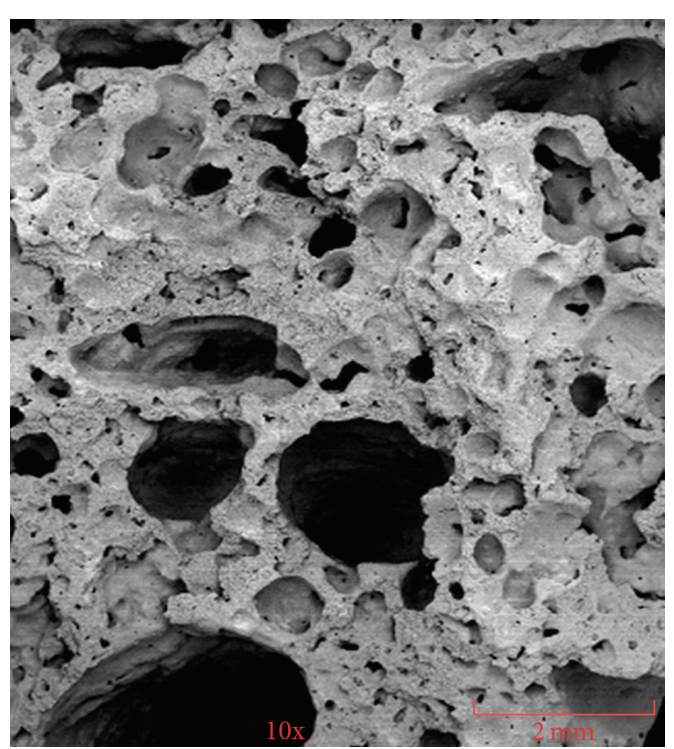

(b)

FIGURE 2: Fracture surfaces of samples with (a) the lowest $(0.2 \mathrm{wt} \%)$, and (b) the highest $(0.8 \mathrm{wt} \%)$ aluminum content.

both as a function of $\mathrm{Al}$ powder percentage. As it can be observed, the density did not vary as it was expected for the different $\mathrm{Al}$ amounts. In general, the density of a cellular concrete decreases as the foaming agent percentage increases, due to the higher amount of pores formed. In this case, however, this behavior was just observed for the samples with 0.2 and $0.4 \mathrm{wt} \% \mathrm{Al}$. For the samples with higher quantities of $\mathrm{Al}$ powder the density increased. The same anomalous behavior was noted for the porosity of the ACCC samples. The porosity increased between the specimens $\mathrm{A} 2$ and $\mathrm{A} 4$, but it has subsequently decreased for samples A6 and A8, achieving its higher value on sample A4 (83.2\%).

The analysis of ACCC samples fractured surfaces revealed that mixtures $\mathrm{A} 6$ and $\mathrm{A} 8$ presented pores with a nonuniform shape, which were larger than those observed for mixtures A2 and A4, suggesting the coalescence of the pores of mixtures with higher $\mathrm{Al}$ content. This could explain the nonexpected results for density and porosity. Figures 2(a) and 2(b) show the fracture surface of samples A2 and A8, respectively.

When pores join together, they acquire a higher volume and tend to escape from the material [1] due to the stronger forces exerted on them by the fluid (buoyancy exerted by the cementitious paste on the gas bubbles). In this way, part of the $\mathrm{H}_{2}$ gas formed during the reaction between $\mathrm{Al}$ and hydroxides is not effective for the production of pores, resulting in the lower porosities of samples A6 and A8.

A factor that can explain the pore coalescence occurred to these samples is the high reactivity of the Al powder used in this study. As showed in Figure 1, $0.2 \mathrm{wt} \% \mathrm{Al}$ content was already enough to produce a porosity of $81.8 \%$. When higher 


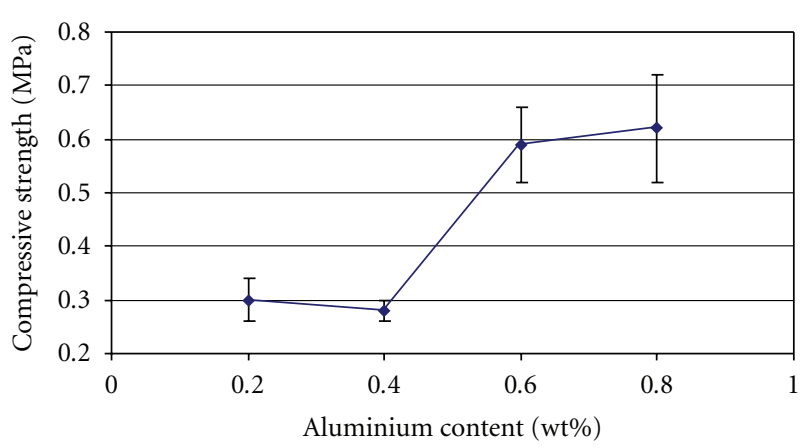

FIgURE 3: ACCC compressive strength as a function of aluminum content. The vertical bars represent the standard deviation of the measured values.

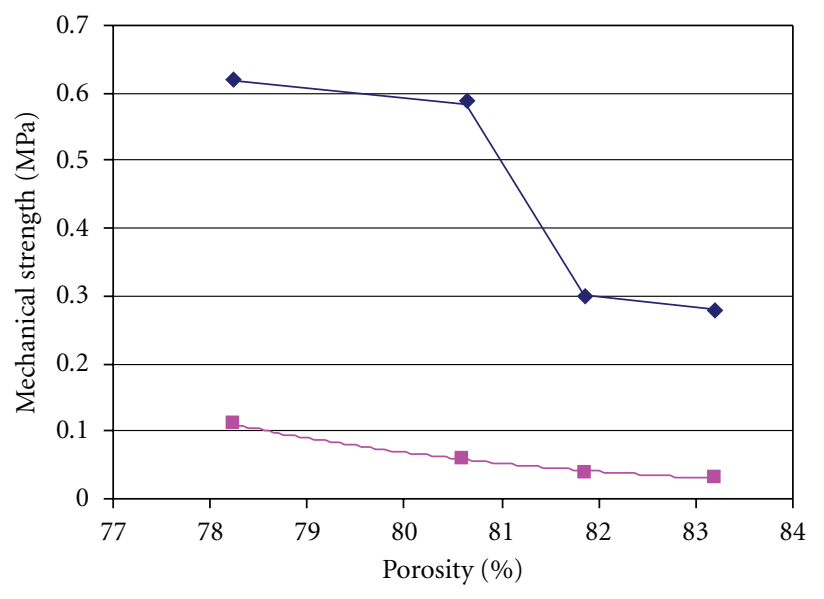

- ACCC investigated in this study

- CCC investigated by Goual, M.S. et al. [6]

FIgUre 4: Compressive strength of the ACCC samples investigated in this study and the estimated values based on the literature for CCC [6].

contents of $\mathrm{Al}$ were added, the amount of hydrogen bubbles formed could have been so high that it was more stable for them to coalesce than to remain isolated. Coalescence provides a minimization of the pores surface total area, what results in a more stable configuration for the system [11].

Possible solutions for this problem would be to minimize the amount of superplasticizer used in order to increase the viscosity of the cementitious paste so that the escape of the hydrogen bubbles would be detained, and to optimize the amount of Al power used (Stanlux Flake CL4010), since a lower amount of this powder is enough to produce high porosities.

3.2. Mechanical Strength. The mechanical strength of the ACCC samples was consistent with the density and porosity results, that is, higher porosities resulted in lower mechanical strength, what can be observed in Figure 3.

The different mechanical compressive strength values presented by the samples analyzed in this study are a consequence of their cellular morphology. In samples A2

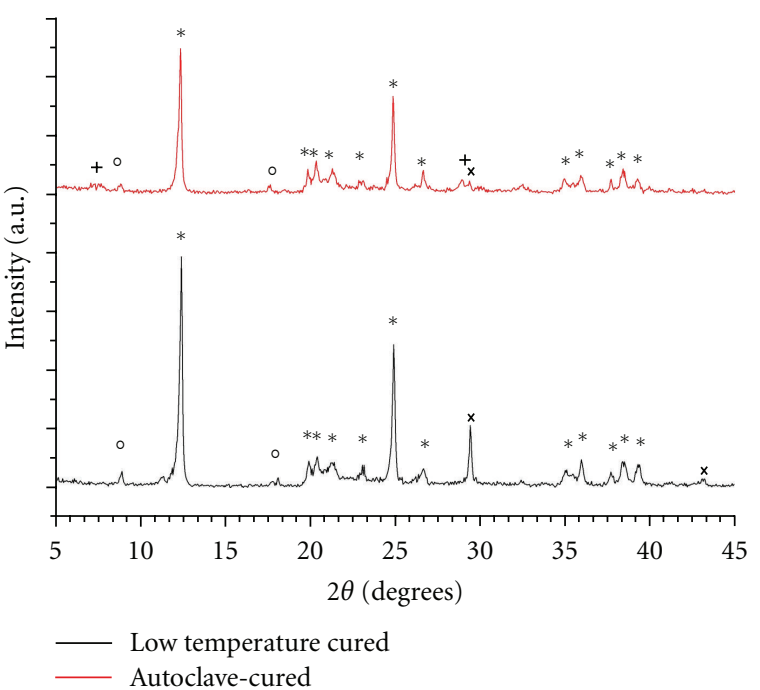

FIGURE 5: XRD diffratograms of samples cured at low temperature $\left(25^{\circ} \mathrm{C}\right.$ for 21 days $)$ and in autoclave $\left(180^{\circ} \mathrm{C}, 12\right.$ atm for 10 hours $)$. Detected phases are kaolinite $(*)$, halloysite $(\circ)$, calcite $(\times)$, and tobermorite $(+)$.

and A4, due to the higher quantity and homogeneous distribution of their pores, the interpore struts are thinner, conferring a lower strength to the material. However, in samples A6 and A8, though the pores are larger due to coalescence, the struts are thicker, what resulted in higher compression strength. Even so, the obtained values were very low, achieving a maximum of $0.62 \mathrm{MPa}$ for the composition A8 (78.23\% porosity).

According to Gibson and Ashby [9], the mechanical strength of a cellular material is a potential function of its relative density, following the equation:

$$
\sigma=\sigma_{o} C_{1}\left(\rho_{\text {rel }}\right)^{n}=\sigma_{o} C_{1}(1-P)^{n},
$$

where $\sigma_{o}$ is the mechanical strength of the totally dense material, $C_{1}$ is a geometrical constant of proportionality, $P$ its porosity and $n$ an empirical exponent.

Through this equation the values of mechanical strength that CCC samples would present if they had same porosities as the ACCC samples analyzed in this study were estimated based on the data provided in the literature [6]. The comparison is shown in Figure 4.

It can be observed that the mechanical strength values estimated for CCC samples are significantly smaller than those measured for the ACCC with same relative densities. This allows the conclusion that autoclaving is effective on strengthening a clayey-based cellular concrete, since for an equal porosity value, the compressive strength of ACCC is substantially higher than that of CCC, which is cured at room temperature.

As the higher compressive strength analyzed in this study was $0.62 \mathrm{MPa}$ for the sample with $0.8 \mathrm{wt} \% \mathrm{Al}$, it becomes clear that a reduction on the amount of the Al powder used is necessary, in order to obtain samples with lower porosities and consequently higher mechanical strength to meet the specifications. However, if the purpose is to use a material 


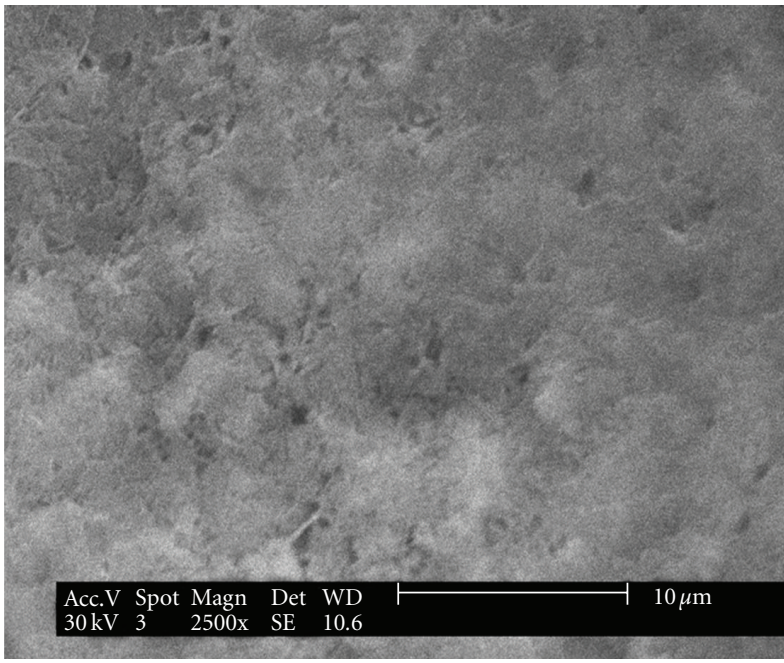

(a)

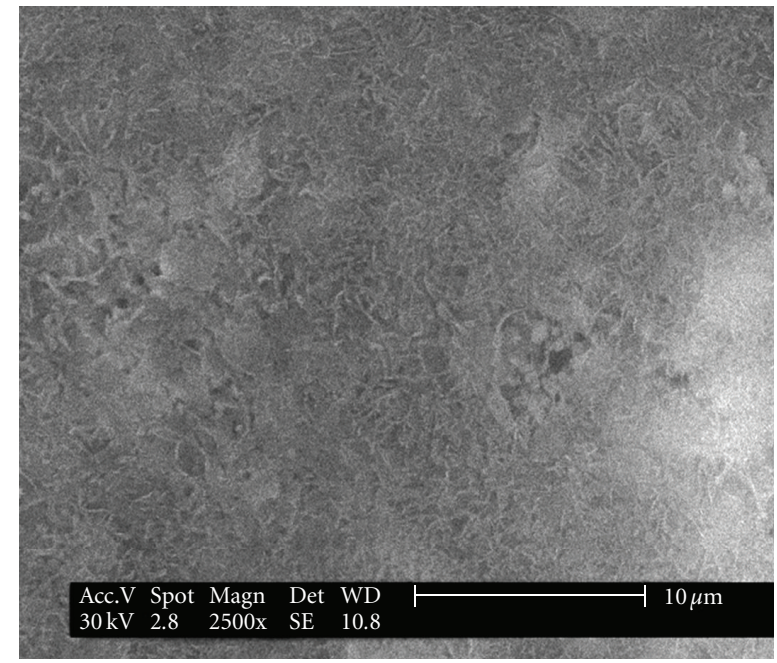

(b)

Figure 6: SEM images of samples cured in (a) at low temperature $\left(25^{\circ} \mathrm{C}\right.$ for 21 days) and (b) autoclave $\left(180^{\circ} \mathrm{C}, 12\right.$ atm for 10 hours).

with similar porosity as the ones here analyzed, some change in composition should be investigated.

3.3. Microstructure and Phase Analysis. The crystalline phases of ACCC were compared to those of a clayey cellular concrete cured at $25 \pm 2^{\circ} \mathrm{C}$ and $90 \% \mathrm{RH}$ for 21 days (Figure 5). Peaks of kaolinite $\left(\mathrm{Al}_{2}\left(\mathrm{Si}_{2} \mathrm{O}_{5}\right)(\mathrm{OH})_{4}\right)$ and halloysite $\left(\mathrm{Al}_{2}\left(\mathrm{Si}_{2} \mathrm{O}_{3}\right)(\mathrm{OH})_{8}\right)$ from nonreacted clay may be observed in both cases. The relative intensity of the calcite $\left(\mathrm{CaCO}_{3}\right)$ peak is decreased when the CCC was autoclaved, giving rise to tobermorite $\left(\mathrm{Ca}_{5} \mathrm{Si}_{6} \mathrm{O}_{17} \cdot 5\left(\mathrm{H}_{2} \mathrm{O}\right)\right)$. Typical needle-like tobermorite structures $[12,13]$ are more visible in the ACCC sample (Figure 6(b)) when compared to the CCC cured at low-temperature (Figure 6(a)).

\section{Conclusions}

This study aimed at investigating the influence of the autoclave curing on the mechanical strength of a clayeybased cellular concrete. Porosity and mechanical strength of samples with different compositions, differing only on the $\mathrm{Al}$ content, were analyzed and the results were compared to the literature for clayey cellular concrete cured at room temperature (CCC).

According to the results, the following could be concluded.

(i) The samples with 0.6 to $0.8 \%$ aluminum powder produced so much hydrogen that the pores no longer remained discrete, that is, the pores coalesced to such an extent the excess hydrogen could escape the matrix. This means that there is likely to be an optimum aluminum addition level in the range 0.4 to $0.6 \%$ to produce maximum porosity.

(ii) The mechanical strength of the ACCC samples varied according to its porosity, that is, it increased as the porosity decreased. However, the obtained values were very low, achieving a maximum of $0.62 \mathrm{MPa}$ for the sample with the lower porosity (78.23\%).

(iii) By extrapolating the data presented in the literature [6] for CCC samples, it was observed that, for the same porosity and composition, Autoclaved Clayey Cellular Concrete (ACCC) presents substantial higher mechanical strength than CCC, thus showing that autoclaving is effective on strengthening this kind of material.

(iv) Lower amounts of $\mathrm{Al}$ powder should be used in order to reduce the porosity and increase the mechanical strength. Another possibility would be an alteration on the solid phase composition of the ACCC here investigated.

\section{Acknowledgments}

The authors are thankful to Mr. Zanon and Mr. Nogara from Celucon (Criciúma, SC, Brazil) for providing the aluminum powder used in this study, as well as permitting them to use their autoclave for our experimental work.

\section{References}

[1] M. W. Grutzek, "Cellular concrete," in Cellular Ceramics: Structure, Manufacturing, Properties and Applications, M. Scheffler and P. Colombo, Eds., pp. 193-223, John Wiley \& Sons, Weinheim, Germany, 2005.

[2] Toolbase Services, "Autoclaved Aerated Concrete (AAC): manufactured building block made of all-natural raw materials," May 2010, http://www.toolbase.org/techinventory/techdetails .aspx? contentdetailid $=690$.

[3] P. J. Tikalsky, J. Pospisil, and W. MacDonald, "A method for assessment of the freeze-thaw resistance of preformed foam cellular concrete," Cement and Concrete Research, vol. 34, no. 5, pp. 889-893, 2004. 
[4] S. Lavalle, "Cellular concrete to the rescue," May 2010, http://www.cellular-concrete.com.

[5] N. Narayanan and K. Ramamurthy, "Microstructural investigations on aerated concrete," Cement and Concrete Research, vol. 30, no. 3, pp. 457-464, 2000.

[6] M. S. Goual, A. Bali, F. de Barquin, R. M. Dheilly, and M. Quéneudec, "Isothermal moisture properties of Clayey Cellular Concretes elaborated from clayey waste, cement and aluminium powder," Cement and Concrete Research, vol. 36, no. 9, pp. 1768-1776, 2006.

[7] M. S. Goual, A. Bali, and M. Quéneudec, "Effective thermal conductivity of clayey aerated concrete in the dry state: experimental results and modelling," Journal of Physics D, vol. 32, no. 23, pp. 3041-3046, 1999.

[8] M. S. Goual, F. De Barquin, M. L. Benmalek, A. Bali, and M. Quéneudec, "Estimation of the capillary transport coefficient of Clayey Aerated Concrete using a gravimetric technique," Cement and Concrete Research, vol. 30, no. 10, pp. 1559-1563, 2000.

[9] L. J. Gibson and M. F. Ashby, Cellular Solids-Structure and Properties, Cambridge University Press, Cambridge, UK, 2nd edition, 2001.

[10] NBR 13439, Blocos de Concreto Celular AutoclavadoVerificação da Resistência à Compressão, ABNT, Rio de Janeiro, Brazil, 1995.

[11] N. Shinohara, M. Okumiya, T. Hotta, K. Nakahira, M. Naito, and K. Uematsu, "Morphological changes in process-related large pores of granular compacted and sintered alumina," Journal of the American Ceramic Society, vol. 83, no. 7, pp. 1633-1640, 2000.

[12] X. Huang, D. Jiang, and S. Tan, "Novel hydrothermal synthesis method for tobermorite fibers and investigation on their thermal stability," Materials Research Bulletin, vol. 37, no. 11, pp. 1885-1892, 2002.

[13] X. Huang, D. Jiang, and S. Tan, "Novel hydrothermal synthesis of tobermorite fibers using Ca(II)-EDTA complex precursor," Journal of the European Ceramic Society, vol. 23, no. 1, pp. 123126, 2003. 

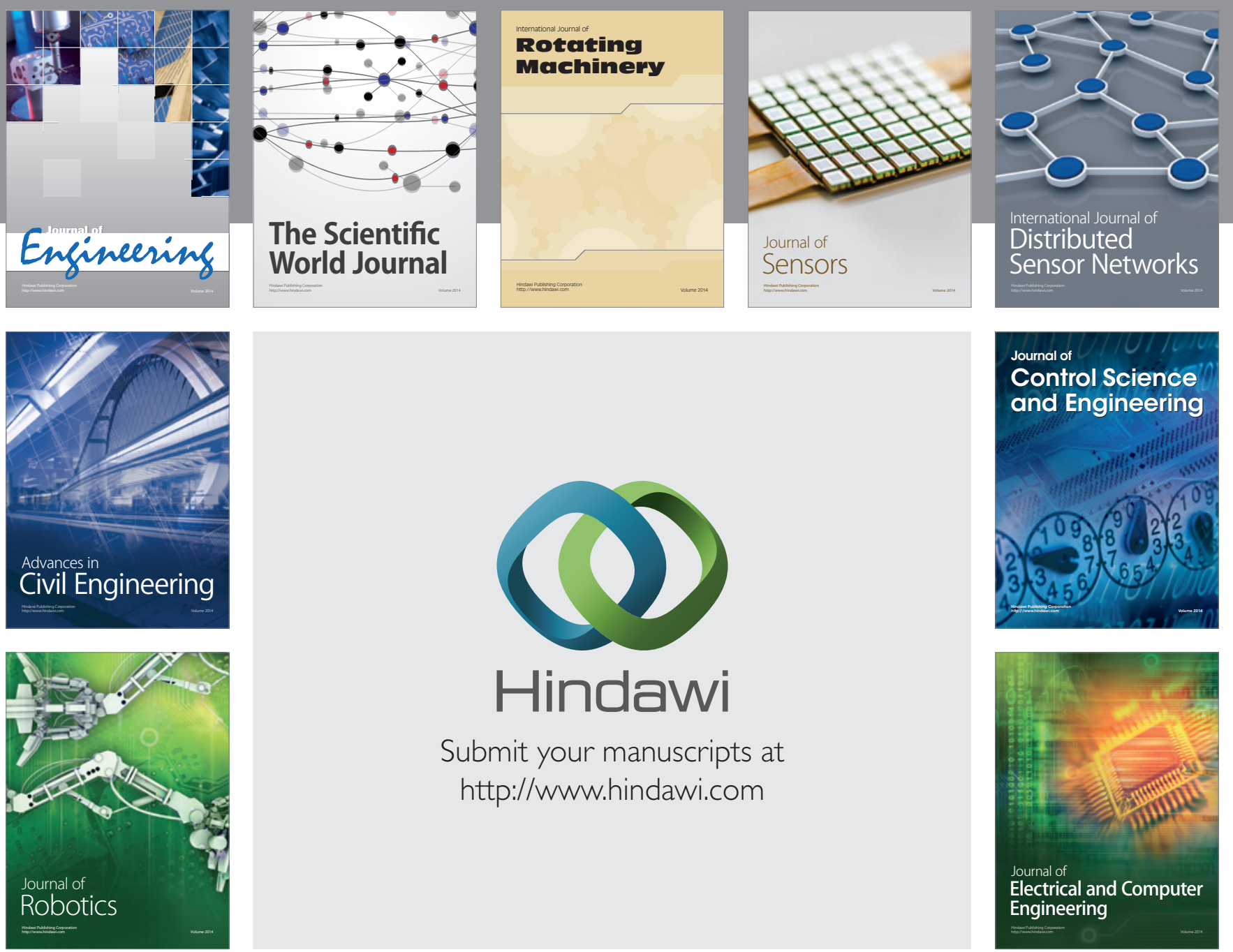

Submit your manuscripts at

http://www.hindawi.com
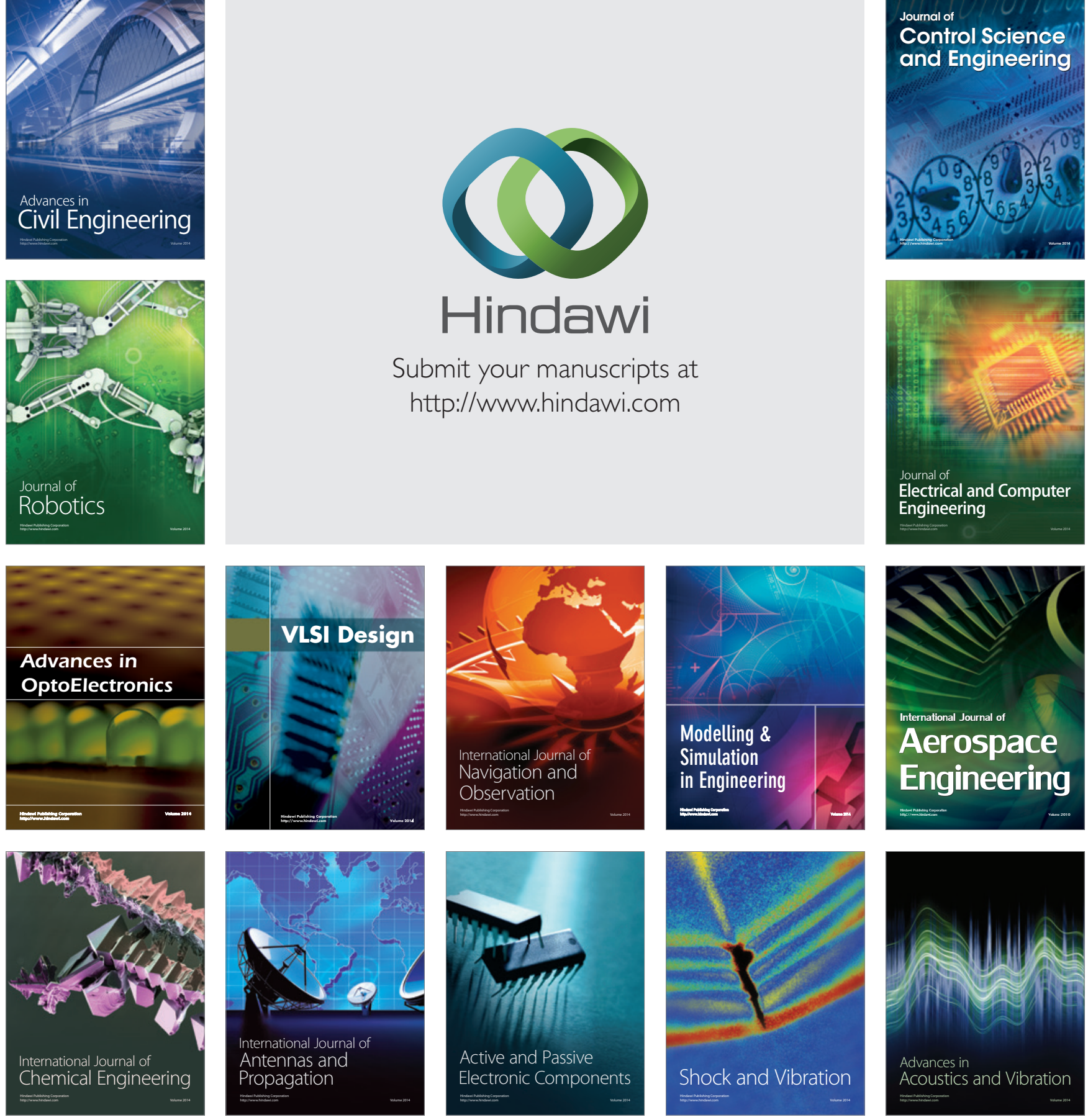